\title{
Implementation of the Perturb and Observe Digital Control Techniques for Photovoltaic Converters
}

\author{
Gehan S. Ahmed \\ Faculty of Engineering \\ Ain Shams University, \\ Cairo, Egypt
}

\author{
Abdelhalim Zekry \\ Faculty of Engineering, \\ Ain Shams University, \\ Cairo, Egypt
}

\author{
Ismail M. Hafez \\ Faculty of Engineering, \\ Ain Shams University, \\ Cairo, Egypt
}

\author{
Mohamed Abouelatta \\ Faculty of Engineering, \\ Ain Shams University, \\ Cairo, Egypt
}

\begin{abstract}
Photovoltaic (PV) is one of the main resources of Renewable Energy, as it is environmental friendly and relatively cost effective. It is utilized to produce electricity from the abundant solar energy. A PV system consists of (PV) array of modules, DC/DC converter with a fixed load and maximum power point tracking MPPT controller. The DC/DC converter is controlled to operate at MPP of the PV array. In this paper a system with a controller based on Perturb and Observe (P\&O) algorithm is implemented in MATLAB/SIMULINK. A new approach has been devised to reach the maximum power point in two steps. The first step is to get Vpvmax and Ipvmax of the array and then get the working value of the duty ratio to operate the DC/DC converter at Imax. The simulation results show the feasibility of the approach. This technique reduces the computational effort of the system.
\end{abstract}

\section{Keywords}

Photovoltaic (PV) System, Maximum Power Point (MPP), Maximum Power Point Tracking (MPPT), Perturbation and Observation $(\mathrm{P} \& \mathrm{O})$ method, DC/DC Converter.

\section{INTRODUCTION}

Energy is never produced but always converted from one form to another. A global energy demand is increased due to rapidly growing of world population, increasing of living standard, and other sources of energy like fossil fuels, oil, coal, and gas are not sustainable energy sources. The fossil fuels get more expensive and they are responsible for global warming and climate change [1].

All these reasons lead to work with solar energy. The solar systems are based on photovoltaic system depicted in Figure 1(a). It is consisted of the photovoltaic array, the DC/DC converter with a fixed load in addition to maximum power point controller. The PV modules are dc power sources. The module in this study consists of 60 polycrystalline silicon solar cells in series and provides 250 of maximum power [2]. The MPPT controller is designed to operate the PV array at its maximum power point with the maximum current $(\mathrm{Im})$ and maximum volt $\left(V_{m}\right)$ by adjusting the duty cycle (D) of the DC to DC converter to transfer the maximum power to the load. The DC/DC converter works as a matching circuit between the fixed load and the variable input impedance PV array. The cause of the variation of the input impedance is the varying incident solar radiation and the temperature.

The proposed operation of the system is as follows: The maximum operating point of the module is determined by scanning one complete I-V and P-V curve to fix the maximum power point of the module $P_{m}, V_{m}$ and $I_{m}$. Then one calculates the input impedance $R_{s}=V_{m} / I_{m}$. Then one calculates the expected duty ratio according to the operating principles of the DC to DC converter.

After that we apply a voltage $V_{m}$ to the converter and verify that it operates at $I_{m}$. If there is any deviation the duty ratio is incremented till difference between the measured current and the Im becomes minimum by scanning.

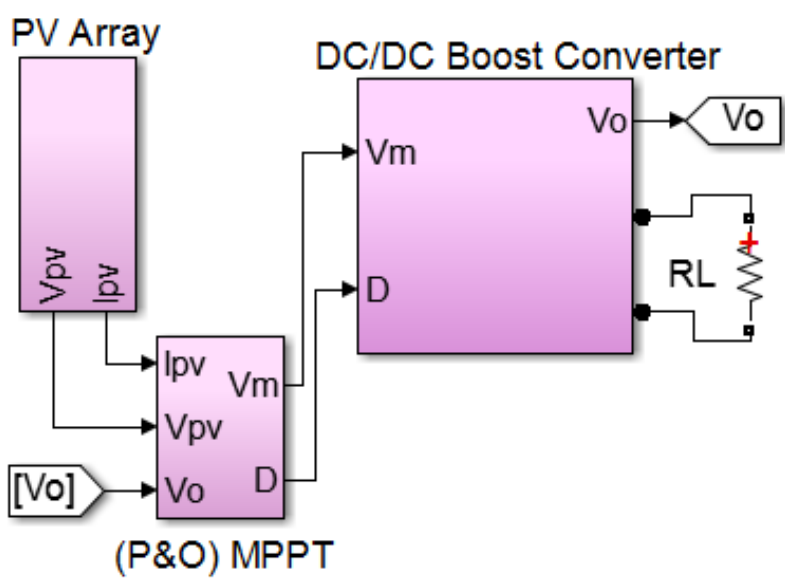

Fig 1(a): Block diagram of the studied PV system

\section{MATHEMATICAL MODELING OF THE PV MODULE}

A simple model of the PV cell in shown in an equivalent circuit in Figure 1 (b). It consists of the following parameters: short circuit current $I_{s c}$, reverse saturation current, $I_{o}$, series resistance $R_{s}$, Parallel resistance $R_{p}$, and the diode ideality factor $n . n$ is in range $1<n<2$, where $n=1$ for ideal diode.

The current- voltage relationship of the PV cell is given by [3]:

$$
I=I_{s c}-I_{o}\left[e^{q\left(\frac{V+I \cdot R_{s}}{n k T}\right)}-1\right]-\left(\frac{V+I \cdot R_{s}}{R_{p}}\right)
$$

Performance parameters affecting the PV cell: $R_{s}$ is multiplied by the number of cells. $R_{p}$ less affecting than $R_{s}$ and only noticeable when the PV modules are connected in parallel. Besides it contains a single diode which provides relatively accurate model, also the effect of reverse saturation current $I_{o}$ and short circuit current $I_{s c}$ can be considered for more precise model.

The modeling of the PV module is the same of the PV cell. It uses the same model, parameters, and current but the voltage of the module must be divided by the number of cells [3].

$$
V_{\text {cell }}=\frac{V_{\text {module }}}{N_{s}}
$$

Where $N_{s}$ is the number of series cells 


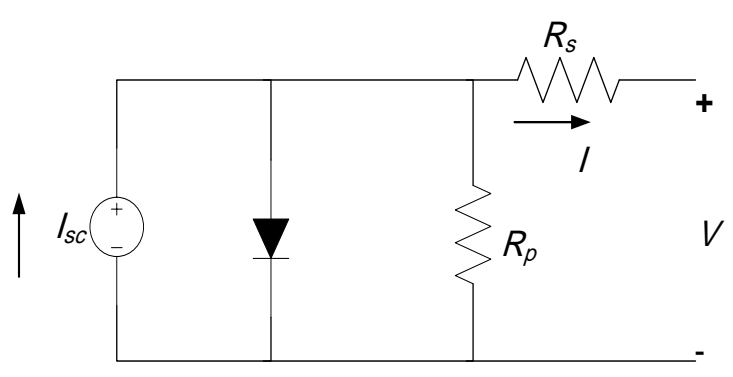

Fig 1(b): Equivalent circuit of PV cell

\subsection{Photovoltaic Array Characteristics}

In this study a polycrystalline silicon module with maximum power output at AM1 is utilized to build the system. According to the manufacturer data sheet [2] it has the specifications: short circuit current $I_{s c}=8.85 \mathrm{~A}$, open circuit voltage $V_{o c}=37.6 \mathrm{~V}$, maximum current $I_{m}=8.2 \mathrm{~A}$, maximum voltage $V_{m}=30.4 \mathrm{~V}$ and maximum power $P_{m}=250 \mathrm{~W}$. Photovoltaic has an optimum operating point called MPP. I-V and P-V Characteristic curves are shown in Figure 2(a) and 2(b). The model of the Photovoltaic module is shown in Figure 2(c). It contains physical solar cell supplied by $1000 \mathrm{~W} / \mathrm{m}^{2}$ irradiance and adjusted at $25^{\circ} \mathrm{C}$, variable load starts from 0 to infinity $\left(R_{\text {amp }}\right)$ in order to scan the full characteristic curve from $I_{s c}$ to $V_{o c}$, Simulink-PS converter to convert electrical (I or V) signal into physical signal, a product to compute power from $I$ and $V$, graphs to display I-V and $\mathrm{P}-\mathrm{V}$ curves, converters to convert simulink signal into physical signal (identified in Figure 2(c) by Simulink-PS converter2), solver configuration for the physical network to specify the solver parameters needed and electrical reference which represents electrical ground. Power increases as voltage increases reaching the peak value and decreases as the resistance increases to a point where current drops off. This is the point where the load matched the solar panel resistance at a certain level of temperature and insolation [4].

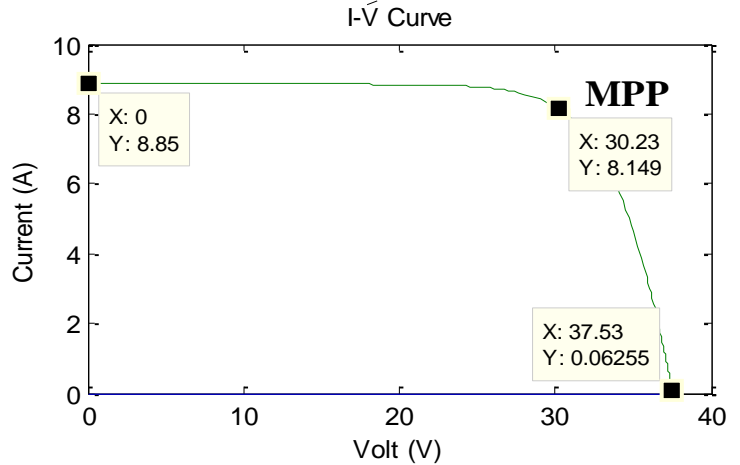

Fig 2(a): I-V Characteristics of PV

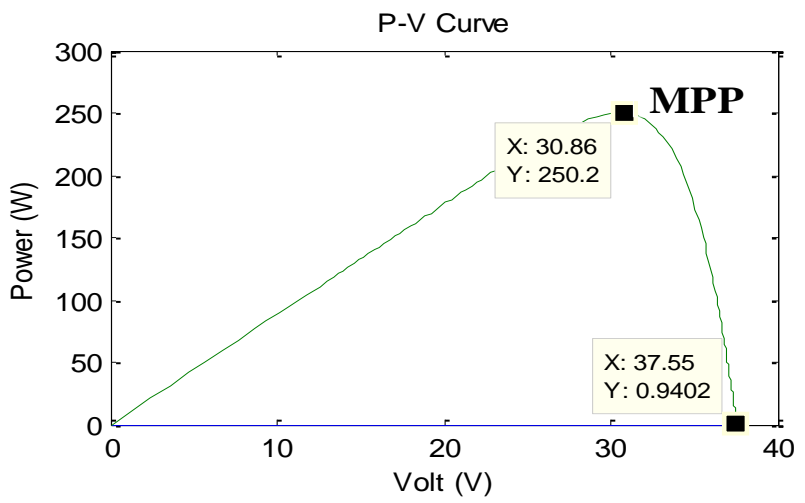

Fig 2(b): P-V Characteristics of PV

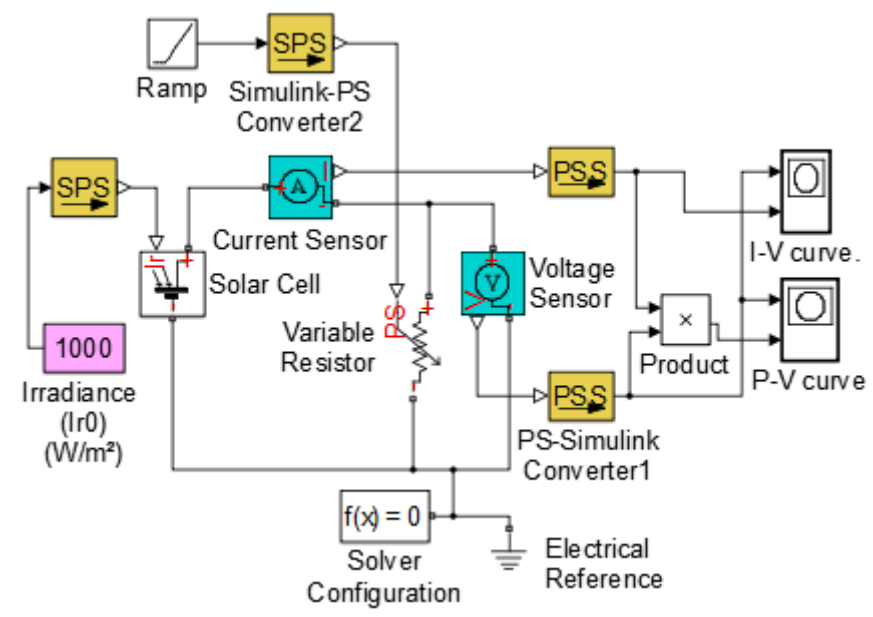

Fig 2(c): The model of the PV module for I-V and $P-V \mathrm{ch} / \mathrm{s}$

\subsection{The DC/DC converter}

The DC/DC converter used in the system is the boost type with the configuration shown in Figure 3. The model composed of PV array is the power dc source, (P\&O) MPPT adjusts the $D$ in order to keep the DC/DC converter work at MPP and compute $V_{m}$. Vm is the controlled voltage source for the converter. It is designed to have the specification described in Table 1. The DC/DC boost converter works as a matching circuit between PV array and a load. The following parameters affect the performance of the converter: Voltage gain $A_{v}$, Current gain $A_{i}$, input impedance $R_{i n}$, boundary filter inductance $L_{b}$, and minimum filter capacitance $C_{\min }$. The boost converter stability is reduced due to its sensitivity to the variation of duty cycle in $A_{v}$ and $A_{i}$ [5]. In order to operate the converter at MPP a matching between the input impedance $R_{s}$ of the PV array and the input impedance $R_{i n}$ of the converter must be satisfied. This is done by adjusting the duty cycle of the converter. The converter can operate in two distinct modes CCM where $I_{L}>0$ which preferred for high efficiency and CCM where $I_{L}=0$ during the switching period.

Table 1. DC/DC Boost Converter Parameter
\begin{tabular}{|c|c|}
\hline Parameter & Value \\
\hline Inductance, $L$ & $2488.74 \mu \mathrm{H}$ \\
\hline Capacitance, $C_{\text {out }}$ & $120 \mu \mathrm{F}$ \\
\hline Mosfet Switch & $38 \mathrm{~A}, 600 \mathrm{~V}$ \\
\hline Diode & $20 \mathrm{~A}, 600 \mathrm{~V}$ \\
\hline Switching Frequency, $f_{s}$ & $19 \mathrm{kHz}$ \\
\hline Load Resistance, $R_{L}$ & $55 \Omega$ \\
\hline Duty cycle, $D$ & 0.631 \\
\hline Maximum PV Voltage, $V_{m}$ & $60.73 \mathrm{~V}$ \\
\hline
\end{tabular}

\subsubsection{DC/DC Boost Converter Design}

Boost Ratio

$A_{v}=\frac{V_{o}}{V_{s}}=\frac{V_{o}}{V_{m}}=\frac{1}{1-D}$

Where $V_{o}$ is the output Voltage from converter and D is the duty ratio

$D=1-\frac{V_{m}}{V_{o}}$ 
Inductor selection

$L=\frac{V_{m} \times D}{\Delta I_{L} \times f_{s}}$

$\Delta I_{L}$ is inductor current ripple [6-8].

The maximum power transfer when input impedance Rin of the converter matches the input impedance $R_{s}$ of the PV module Equation (3) [9]. The following system is designed by adjusting duty cycle $D$ with respect to the load from the Equation (6),

$R_{\text {in }}=\frac{V_{s}}{I_{s}}=R_{\text {in }}=R_{S}=\frac{V_{m}}{I_{m}}$

$A_{i}=\frac{I_{o}}{I_{s}}=\frac{I_{o}}{I_{m}}=(1-D)$

$I_{o}$ is the output current of the converter, $V_{s}$ voltage source, and $I_{s}$ is the current source. $R_{\text {in }}$ of the boost converter

From Equation (1) and (4),

$R_{\text {in }}=\frac{V_{m}}{I_{m}}=\frac{V_{o}(1-D)^{2}}{I_{o}}=R_{L}(1-D)^{2}$

$D=1-\sqrt[2]{\frac{R_{i n}}{R_{L}}}$

Output capacitor selection

$C_{\text {out }}=\frac{I_{o} \times D}{f_{s} \times \Delta V_{o}}$

$\Delta V_{o}$ is the output voltage ripple [6-8].

The average boundary value of the filter inductance and capacitance between CCM and DCM is

For CCM $L>L_{b}$ and $C_{\text {out }}>C_{\min }$

$L_{b}=\frac{(1-D)^{2} \times D \times R_{L}}{2 \times f_{s}}$

$C_{\text {min }}=\frac{V_{o} \times D}{\Delta V_{o} \times R_{L} \times f_{S}}$

$f_{S}$ is the switching frequency, $\Delta V_{o}$ is the output voltage ripple, $D$ Duty cycle, $R_{L}$ load resistance, $V_{o}$ is the output voltage of the converter.

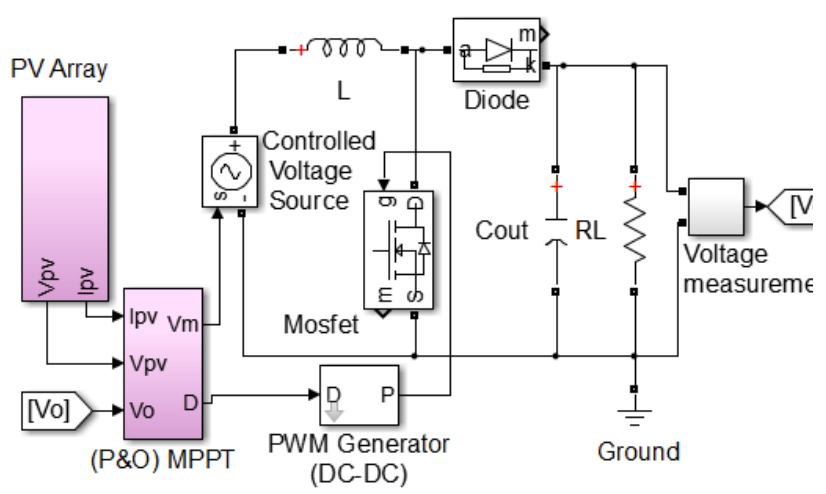

Fig 3: DC/DC Boost converter Simulink Model

\section{MPPT ALGORITHM}

If the irradiance or temperature is changed, the I-V or P-V $\mathrm{Ch} / \mathrm{s}$ will change as well and hence the position of MPP will shift. Therefore changes in the I-V curve have to be tracked continuously to adjust the operating at MPP [1]

There are many techniques:
Fractional open circuit voltage, Perturb and Observe $(\mathrm{P} \& \mathrm{O})$, and Incremental conductance. In this paper $(\mathrm{P} \& \mathrm{O})$ method will be discussed as it is the simplest method.

\subsection{P\&O Algorithm}

Perturb and Observe $(\mathrm{P} \& \mathrm{O})$ is the simplest method in tracking algorithm [10] Figure 4 shows the flow chart $[9,11]$. The duty cycle D is initializing from simulink model according to the boost ratio Equation (1). The present Ipv and Vpv are sensed for calculating $P_{P V} . P_{P V}$ is compared with its previous value $P_{P V}(\mathrm{k}-1)$

If the power increases switch for the voltage $V(k)$ with its previous value $V(k-1)$ in case of voltage increasing keep the voltage change in the same direction of the previous one $(\mathrm{V}+$ $\Delta \mathrm{V})$ else change the voltage in the opposite direction of the previous one $(\mathrm{V}-\Delta \mathrm{V})[12]$. And vise versa in case of power decreasing

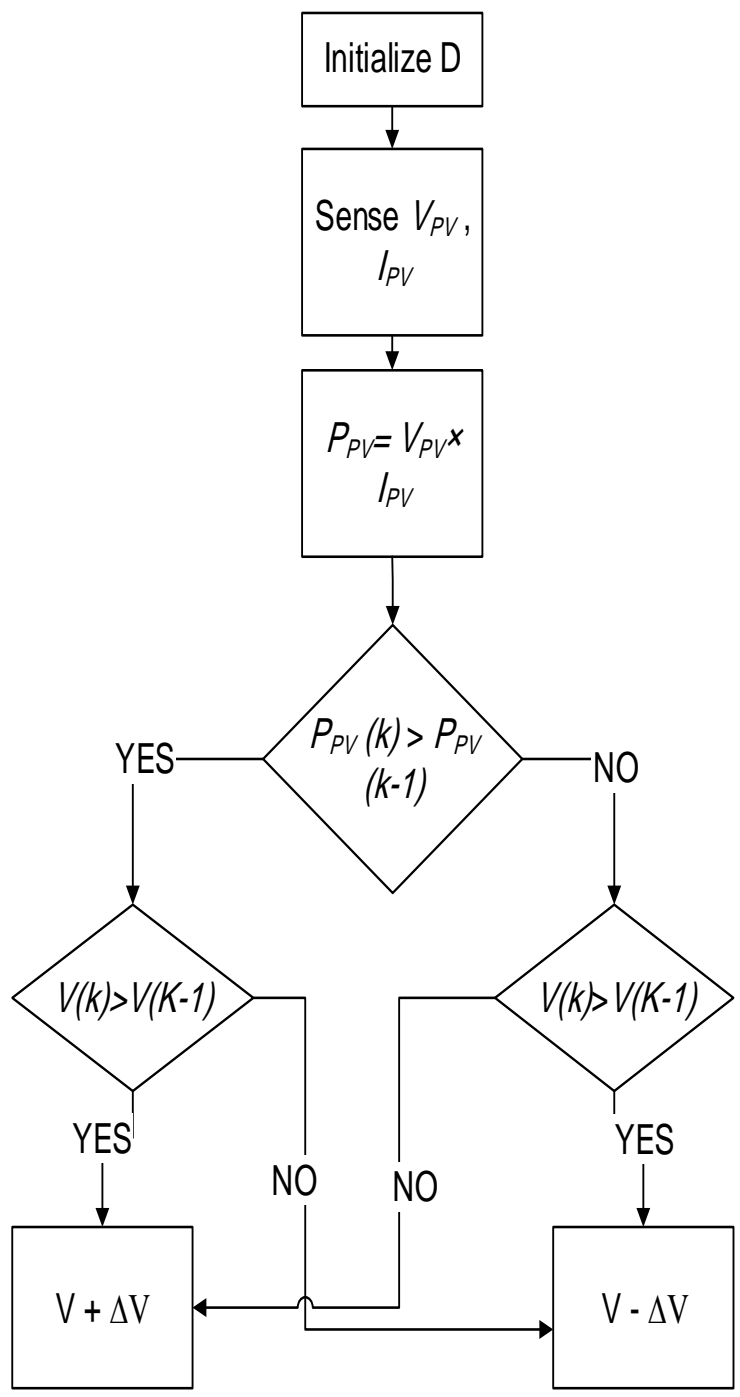

Fig 4: Flow Chart of (P\&O) Algorithm Model where $\mathrm{K}$ is a Sample

\section{2 (P\&O) Algorithm Model}

The model in Figure 5(a) is used to compute $V_{P V \max }$. It is composed of four stages. The first stage designed for comparing $P(k)$ with its previous value $P(k-1)$ to scan for maximum power which will be achieved when the condition is false. In the second stage $V(k)$ is also compared with $V(k-1)$ to decide the direction of $V(k)$ according to Table 2 . In the 
third stage a conditional switch (identified in Figure 5(a) by Switch) is used to $\operatorname{sign} V(k)$ by + or - delta (delta $=0.001$ identified in Figure 5(a) by constant2) according to Exclusive NOR (NXOR block identified by logical operator) which described in table 2 . In the fourth stage when $V(k)$ reached its maximum value $\left(V_{P V \max }\right)$ at $\mathrm{A}=0$ (falling edge) the monostable block is true which inverted to false by the logical operator NOT (identified by logical operator 4) to disable the in/out subsystem (identified by Enabled Subsystem) and stop the $V(k)$ variation as it is reached its maximum $\left(V_{P V \max }\right)$. The saturation (Saturation 2 block) is synchronizing the sample time with the transport delay (identified by transport delay 3 ).
And finally the memory blocks to return to second stage. Figure 5 (b) shows a similar approach of (P\&O) Simulink model in Figure 5(a) with respect to $I_{P V \max }$.

Table 2. Exclusive NOR

\begin{tabular}{|c|c|c|c|}
\hline $\begin{array}{c}\mathbf{A}= \\
\boldsymbol{P}(\boldsymbol{k}) \boldsymbol{>}\end{array}$ & $\begin{array}{c}\mathbf{B}= \\
\boldsymbol{V}(\boldsymbol{k})>\end{array}$ & Output & $\begin{array}{c}\text { State (according to the } \\
\text { design in Figure 5(a)) }\end{array}$ \\
\hline $\boldsymbol{V}(\boldsymbol{k}-\mathbf{k})$ & & At $)$ & $P_{P V \max }$ \\
\hline 0 & 0 & True & At $P_{P V \max }$ \\
\hline 0 & 1 & False & $V_{P V}-$ delta \\
\hline 1 & 0 & False & $V_{P V}+$ delta \\
\hline 1 & 1 & True & \multicolumn{2}{|c}{} \\
\hline
\end{tabular}

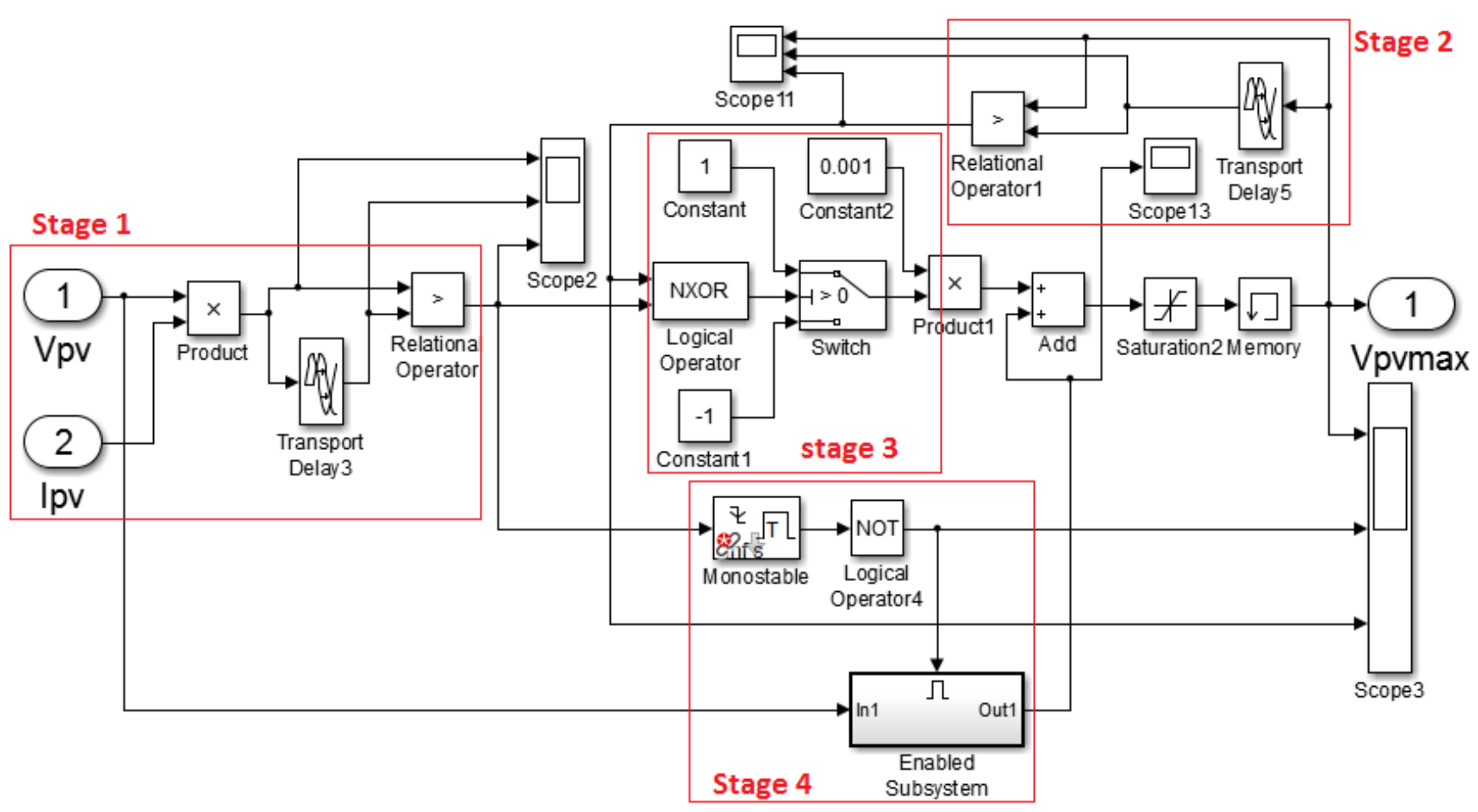

Fig 5 (a): The new approach of (P\&O) Algorithm Simulink model to compute $V_{P V \max }$ [9]

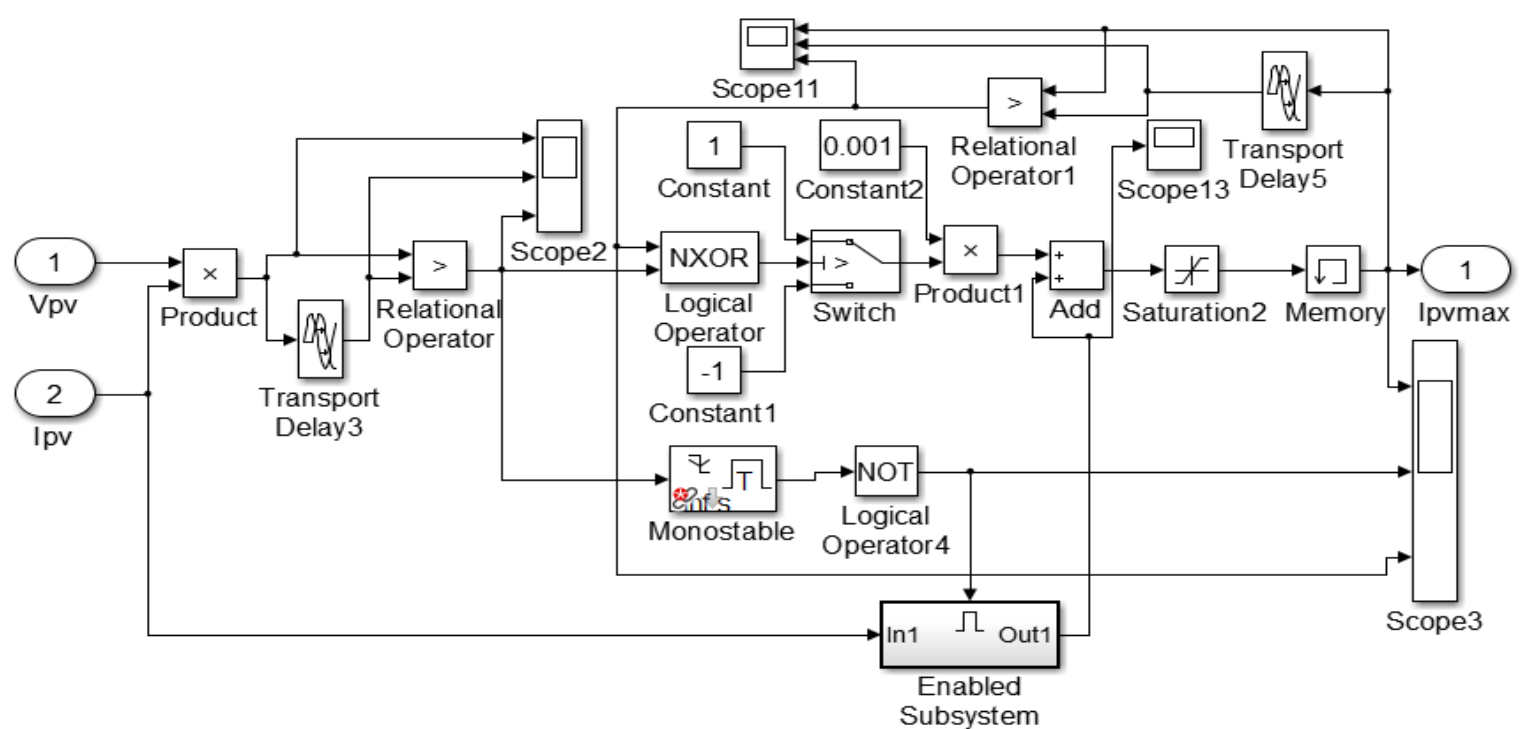

Fig 5(b): The new approach of (P\&O) Algorithm Simulink model to compute $I_{P V \max }$ [9] 


\section{SIMULATION RESULTS}

A new approach of MPPT operates the PV Array at maximum Volt $V_{P V \max }=60.73 \mathrm{~V}$ as shown in Figure 6(a), maximum current $I_{P V \max }=8.183 \mathrm{~A}$ as shown in Figure $6(\mathrm{~b})$ and at maximum power $P_{P V \max }=496.9 \mathrm{~W}$ as shown in Figure $6(\mathrm{~d})$.

A matching between PV array and the DC/DC converter for maximum power transfer is achieved when the input impedance $R_{s}$ of the PV array matches the input impedance of the boost converter $R_{i n}$. $V_{P V \max }=V_{m}$ is applied to the converter. When $I_{D \text { Cavg }}=I_{P V \max }$, the converter works at $I_{m}$. Figure 6(b) shows the $I_{P V \max }=8.183 \mathrm{~A}$ and Figure 6(c) shows the average dc current in the inductor $I_{D C a v g}=8.105 \mathrm{~A}$.

Assume ideal parameters a boost converter boosts the volt from $V_{i n}=60.7 \mathrm{~V}$ to $V_{o}=164.5 \mathrm{~V}$. Figure 7 (a) shows $V_{o}$. While current is decreased to $I_{o}=2.99 \mathrm{~A}$ as shown in Figure 7(b), and output power is slightly decreased to $P_{o}=491.855 \mathrm{~W}$ due to ripples as shown in Figure 7(c).

Figure 8 shows the whole PV system circuit design which composed of the PV modules, MPPT control, DC/DC boost converter and a fixed load.

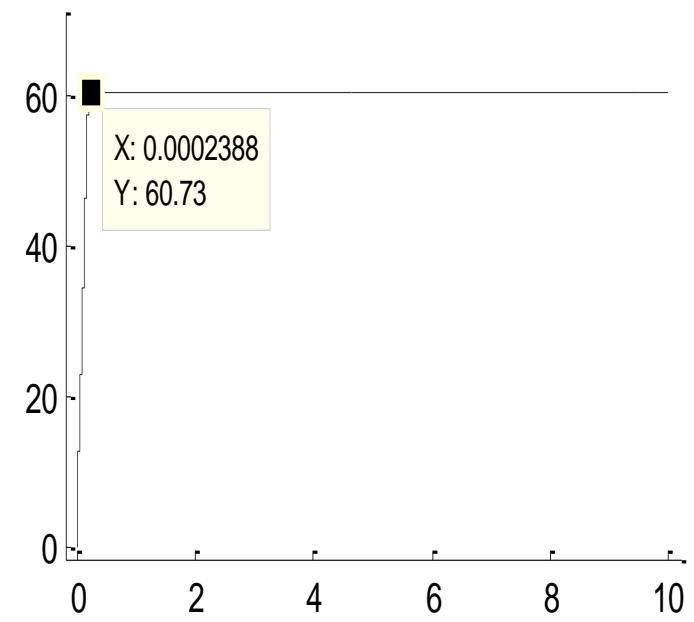

Fig 6(a): Maximum PV volt $V_{P V \max }=60.73 \mathrm{~V}$

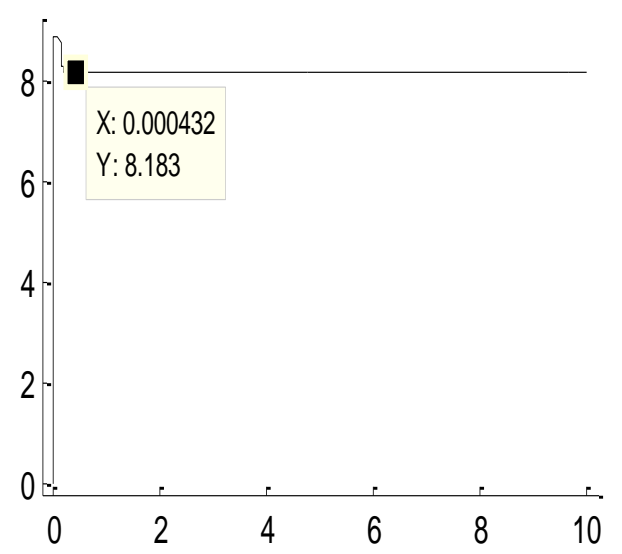

Fig 6(b): Maximum PV current $I_{P V \max }=8.183 \mathrm{~A}$

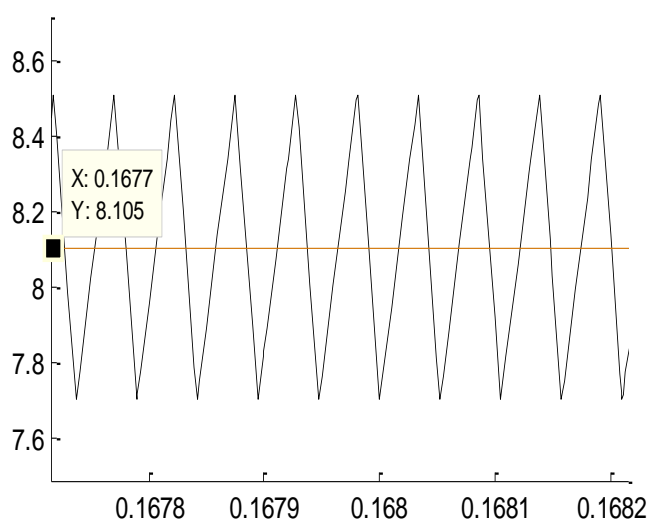

Fig 6(c): Average de current in the inductor $I_{D C a v g}=$ 8. 105A

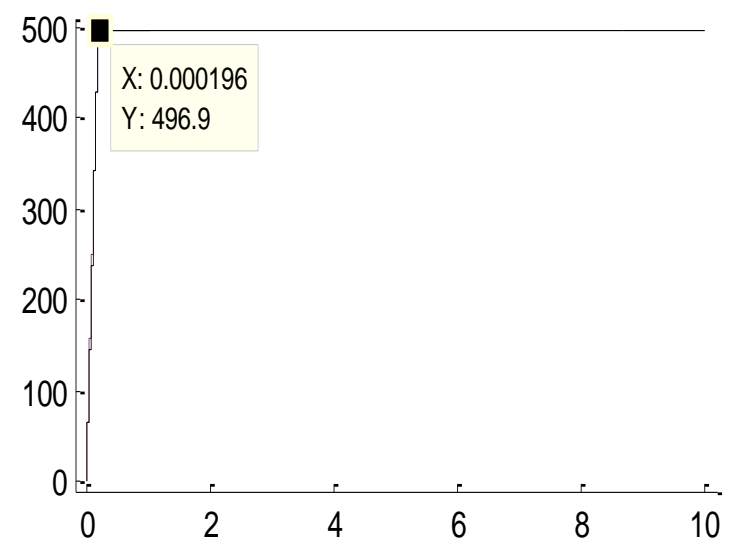

Fig 6(d): Maximum PV Power $P_{P V \max }=496.9 \mathrm{~W}$

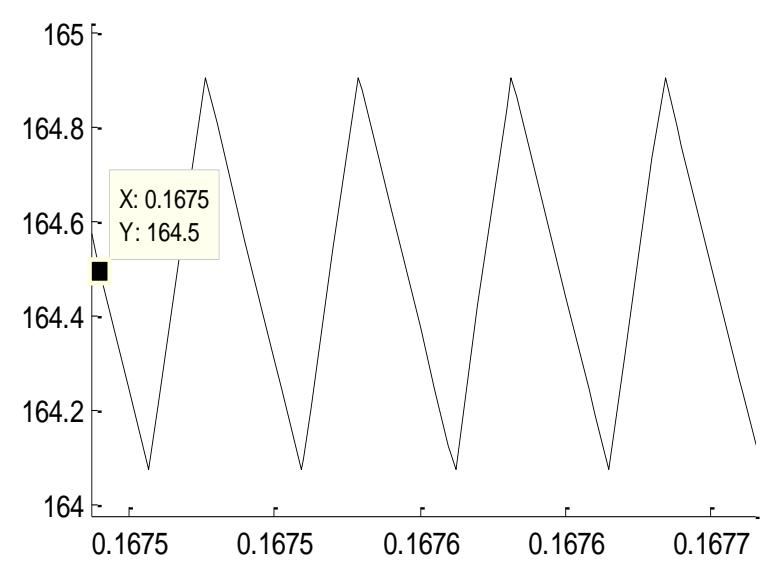

Fig 7(a): The output voltage $V_{o}=164.5 \mathrm{~V}$ 


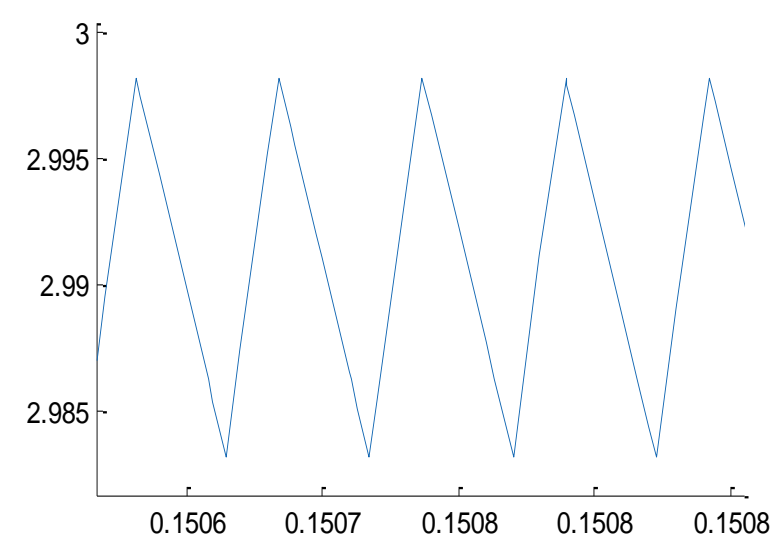

Fig 7(b): output current $I_{\text {out }}=2.99 \mathrm{~A}$

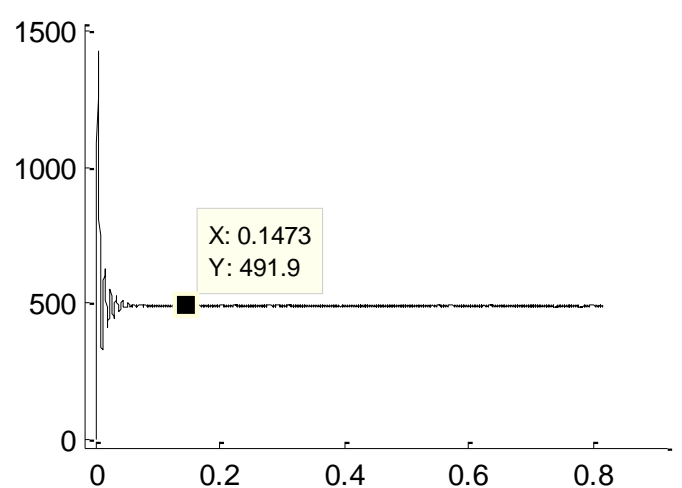

Fig 7(c): The output power $P_{o}=491.9 \mathrm{~W}$

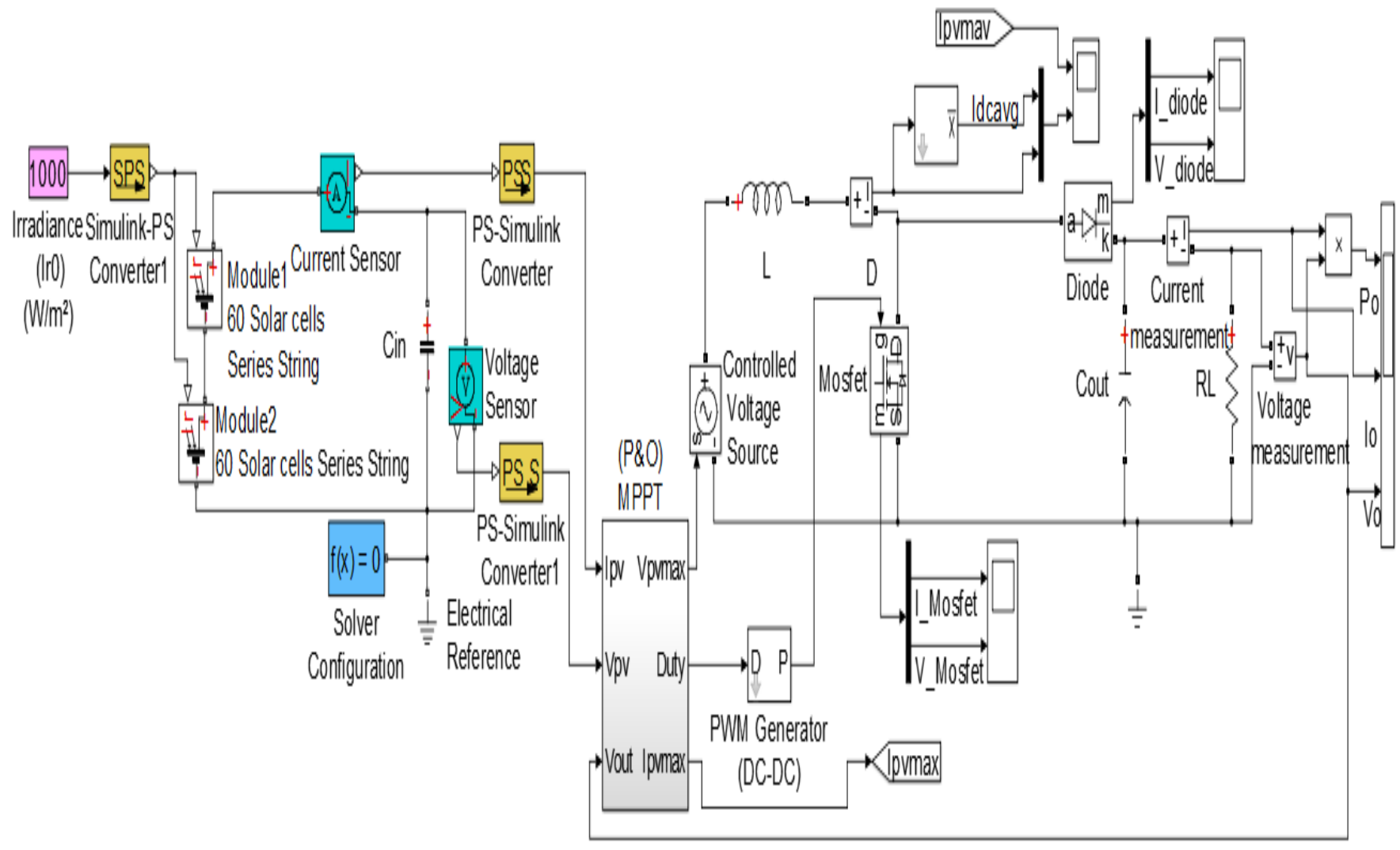

Fig 8: The Proposed PV System circuit diagram

\section{CONCLUSION}

In fact $(\mathrm{P} \& \mathrm{O})$ algorithm model is presented in many different techniques. This paper presents a new approach in the MPPT control technique using ( $\mathrm{P} \& \mathrm{O})$ algorithm model to compute $I_{P V \max }$ and $V_{P V \max }$. The proposed model implemented in MATLAB/SIMULINK model. It depends on comparing $P(k)$ with its previous value $P(k-1)$ and $V(k)$ with its previous value $V(k-1)$ to determine the direction of movement. Once the power has reached its maximum value the simulation stops at a maximum pointed value for $I_{\max }$ and $V_{\max }$. A design of DC/DC boost converter is also presented which operates as a matching circuit by adjusting duty cycle. The duty cycle is calculated at MPP based on the operation of the DC/DC converter. Then Imax is checked. Then the DC/DC converter is checked to operate at $I_{\max }$. It is found that the output power is slightly affected by the ripples. This model will be implemented experimentally in the near future.

\section{REFERENCES}

[1] Klaus Jager, Olindo Isabella, Arno H.M.Smets, Rene' A.C.M.M., Van Swaaij, Miro Zeman, "Solar Energy fundamentals, technology, and systems", 2014.

[2] Polycrystalline Module ISF-250P datasheet, 2013.

[3] Akihiro Oi, "Design and Simulation of Photovoltaic Water Pumping System", Msc thesis, Univ. of California Polytechnic; 20

[4] Muhammad H. Rashid "Power electronics-circuits, devices and applications", 3rd edition; 2011.

[5] M.A. Farahat, H.M.B. Metwally, Ahmed Abd-Elfatah Mohamed, "Optimal Choice and Design of Different Topologies of DC-DC Converter used in PV System, at Different Climate Conditions in Egypt", Renewable Energy 43(2012) 393-402 
[6] William K. Francis, "Matlab/Simulink PV module Model of P\&O and DC link CDC MPPT Algorithms with Lab view Real Time Monitoring and Control over P\&O Technique", IJAREEIE, Vol. 3, special issue 5, December.

[7] Ned Mohan, Tore M. Undeland, and William P. Robbins, "Power Electronics, Converter, Application, and Design”, Third Edition, 2003

[8] Brigitte Hauke,"Basic Calculation of a Boost Converter's Power Stage", SLVA372C-November 2009-Revised January 2014, application report.www.ti.com.

[9] David Jahanbakhsh, "Implementation of DC-DC Converter with Maximum Power Point Tracking Control for Thermoelectric Generator applications", Msc thesis, Royal institute of Technology, Stockholm, Sweden 2012

[10] A.Yafaoui, B. WU and R. Cheung, "Implementation of Maximum Power Point Tracking Algorithm for Residential Photovoltaic Systems", 2nd Canadian Solar Buildings Conference Calgary, June 10-14, 2007

[11] C. Liu, B. Wu and R. Cheung, "Advanced algorithm for MPPT control of Photovoltaic Systems", Canadian solar building conference, Montreal, August 20-24, 2014.

[12] Jancarle L. Santos, Fernando Antunes, Anis Chehab, Cicero Cruz, "A Maximum Power Point Tracker for PV System using a High Performance Boost Converter", Solar Energy 80(2006) 772-778. 